\title{
Hex open Psychological morbidity among suicide-bereaved and non-bereaved parents: a nationwide population survey
}

\author{
Pernilla Omerov, ${ }^{1,2}$ Gunnar Steineck, ${ }^{2,3}$ Tommy Nyberg, ${ }^{3}$ Bo Runeson, ${ }^{1}$ \\ Ullakarin Nyberg ${ }^{1,2}$
}

To cite: Omerov $P$,

Steineck G, Nyberg T, et al. Psychological morbidity among

suicide-bereaved and nonbereaved parents: a nationwide population survey. BMJ Open 2013;3:e003108. doi:10.1136/bmjopen-2013003108

- Prepublication history for this paper is available online To view these files please visit the journal online (http://dx.doi.org/10.1136/ bmjopen-2013-003108).

Received 23 April 2013 Revised 1 July 2013 Accepted 19 July 2013

\footnotetext{
${ }^{1}$ Department of Clinical Neuroscience, Stockholm Centre for Psychiatric Research and Education, Karolinska Institutet, Stockholm, Sweden ${ }^{2}$ Division of Clinical Cancer Epidemiology, Department of Oncology-Pathology, Karolinska Institutet, Stockholm, Sweden

${ }^{3}$ Division of Clinical Cancer Epidemiology, Department of Oncology, Institute of Clinical Sciences, Sahlgrenska Academy, Gothenburg, Sweden
}

\section{Correspondence to} Dr Pernilla Omerov; Pernilla.0merov@ki.se

\begin{abstract}
Objective: To determine how psychological premorbidity affects the risk of depression in parents who lost a child through suicide.

Design: Population-based survey.

Setting: Sweden, between 2009 and 2010.

Participants: All parents who lost a child, age 15-30, through suicide between 2004 and 2007 according to National population registries. Non-bereaved parents matched for age, sex, living area, marital status, number of children. Exclusion criteria: born outside a Nordic country, not Swedish speaking, contact details missing. Participants: 666 of 915 (73\%) suicidebereaved and 377 of 508 (74\%) non-bereaved parents. Main outcome measures: Depression measured by the nine-item depression scale of the Patient Health Questionnaire (PHQ-9) and study-specific questions to assess psychological premorbidity and experience of the child's presuicidal morbidity.
\end{abstract}

Results: In all, 94 (14\%) suicide-bereaved and $51(14 \%)$ non-bereaved parents (relative risk 1.0; 95\% $\mathrm{Cl} 0.8$ to 1.4) had received their first treatment for psychological problems or had been given a psychiatric diagnosis more than 10 years earlier. The prevalence of moderate-to-severe depression was $115(18 \%)$ in suicide-bereaved versus $28(7 \%)$ in non-bereaved parents (RR 2.3; $95 \% \mathrm{Cl} 1.6$ to 3.5). For those without psychological premorbidity, the relative risk was $2.3(95 \% \mathrm{Cl} 1.4$ to 3.6$) .339$ (51\%) suicidebereaved parents expressed worry over the child's psychological health during the month preceding the suicide and 259 (39\%) had anticipated the suicide.

Conclusions: In parents who lost a child through suicide in Sweden we did not find a higher prevalence of long-term psychological premorbidity than among parents who had not lost a child; the more than twofold risk of depression among the bereaved can probably be explained by the suicide and the stressful time preceding the suicide.

\section{INTRODUCTION}

Suicide-bereaved parents are at risk of developing mental disorders that might become long-lasting and life-threatening. ${ }^{1-6}$ The

\section{ARTICLE SUMMARY}

Article focus

- Depression is common in parents who have lost a child through suicide and the condition might become long-lasting and life-threatening.

- As yet, we do not know to what extent psychological premorbidity influences the outcomes of the bereavement.

- Previous studies have not disentangled longterm psychological premorbidity such as psychiatric diseases from short-term psychological premorbidity due to stress related to parenting a suicidal child.

Key messages

- Our study suggests that suicide-bereaved and non-bereaved parents' prevalence of long-term psychological premorbidity does not differ if measured more than 10 years prior to the suicide and that the more than twofold risk of depression in bereaved parents can be found regardless of long-term psychological premorbidity.

- The elevated risk of depression can probably be explained by the suicide and the stressful time preceding the suicide rather than psychological premorbidity. This adds important information for further intervention studies on the treatment of grief-related depression.

Strengths and limitations of this study

- The study relies on a large sample of suicidebereaved parents and matched controls, all identified through nationwide registers. The data collection includes psychometric measurements as well as study-specific data that cannot be retrieved from patient registers. The participation rate was high among suicide-bereaved and nonbereaved men and women.

- The questions regarding psychological premorbidity cover a large time-span and the answers might be affected by recall-induced problems. The questions do not measure the severity of the psychological premorbidity.

bereavement-outcome is affected by factors related to the traumatic loss and to factors related to the bereaved individual. ${ }^{7-11}$ 
Suicide-bereaved family members may have an increased vulnerability for psychological morbidity due to genetic and environmental factors such as psychiatric illness, personality traits and suicidal behaviour. ${ }^{12-14}$ The majority of suicide-bereaved parents do not suffer from mental disorders prior to the child's suicide, but there is a subgroup that does. ${ }^{15} 16$ In a recent Canadian register study, previous psychological morbidity was found to be more prevalent among suicide-bereaved parents than non-bereaved control parents ${ }^{16}$; we do not know if these results are relevant to European communities.

Grief-related depression might be successfully treated. ${ }^{17}$ The occurrence and aetiology of depression of suicide-bereaved parents are, however, yet to be studied carefully. In this population-based study, we examine the long-term risk of depression among suicide-bereaved and non-bereaved parents, with and without psychological premorbidity. We hypothesised that suicidebereaved parents had a higher prevalence of psychological premorbidity in comparison with non-bereaved parents. We also examine the suicide-bereaved parents experience of the child's presuicidal morbidity during the year preceding the suicide. The parents were identified by nationwide registries and data were collected by a detailed questionnaire. ${ }^{18}$

\section{METHODS}

Subjects

We identified all individuals, 15-30 years old, who died through suicide (ICD 10: X60-X84) between 2004 and 2007 and whose deaths were registered in the nationwide Swedish Cause of Death Register. We thereafter used the unique personal identity numbers and the nationwide Multigeneration Register to identify the bereaved parents. ${ }^{19}$ To be included in the study, the parent had to be born in one of the Nordic countries, be able to communicate in Swedish and have an identifiable address and telephone number. Furthermore, parents that had lost more than one child were excluded. A random sample of non-bereaved parents matched for age, sex, living area, marital status, number of children and with a child that was born in the same year as the deceased child was identified through the Swedish Population Register. The ratio of one non-bereaved to two suicidebereaved gave sufficient statistical power to test our hypotheses regarding depression and anxiety according to a power calculation. The inclusion criteria for the nonbereaved parents were identical to those for the bereaved parents, except that they were not allowed to have lost a child. In total, 915 suicide-bereaved and 508 nonbereaved parents were identified as eligible. The participants gave informed consent before taking part.

\section{Data collection and measurements}

We developed the study design from routines established by the Division of Clinical Cancer Epidemiology. ${ }^{18}$ 20-22 Our study-specific questionnaires were constructed in a preparatory study using mixed methods including 46 suicide-bereaved persons. In this study, we tested all questions, including the psychometric scales described below. ${ }^{18}$ We used four questions with a follow-up question to measure psychological premorbidity: (1) 'Have you ever received treatment for psychological problems such as depression, anxiety, psychosis or personality disorder?' Treatment was defined as treatment prescribed by a physician, for example, medication, electroconvulsive therapy (ECT) or conversational therapy. 'If yes, when did you receive your first treatment?' (2) 'Have you ever been given a psychiatric diagnosis, for example, depression, panic disorder, psychosis or personality disorder?' 'If yes, when were you given your first diagnosis?' (3) 'Have you during a period of your life medicated against anxiety?' 'If yes, when did you take your first medication?' (4) 'Have you during a period of your life medicated against low mood or depression?' 'If yes, when did you take your first medication?' The answer categories were 'more than 10 years earlier' and 'during the last 10 years' for the non-bereaved and 'more than 10 years earlier', 'during the last 10 years, before my child's death' and 'during the last 10 years, after my child's death' for the bereaved. We used psychometric scales for three of our psychological outcomes: the two-item Generalised Anxiety Disorder scale (GAD-2), ${ }^{23}$ the nine-item depression scale of the Patient Health Questionnaire (PHQ-9) ${ }^{24}$ and the Alcohol Use Disorders Identification Test (AUDIT) ${ }^{25}$ Symptoms of anxiety and depression were also assessed by questions based on the Diagnostic and Statistical Manual Fourth Edition (DSM-IV) criteria. $^{26}$ We contacted all eligible parents by sending them an introductory letter and thereafter by telephone and asked for consent to send a questionnaire. We started the data collection in August 2009 and the last questionnaire was returned in December $2010 .^{18}$

\section{Statistical analysis}

We tested for differences in characteristics using Pearson's $\chi^{2}$ test and Wilcoxon-Mann-Whitney's test. We dichotomised scores derived from the psychometric scales using recommended cut-offs. ${ }^{27-29}$ We used logbinomial regression to calculate the relative risks (RR) shown in tables 1-4. We thereafter present RR of the different outcomes adjusting for potential confounders, one variable at a time. For modelling involving more than two explanatory variables, we had to use OR estimated through logistic regression, since log-binomial regression did not converge and failed to produce estimates. We performed a variable selection among the possible confounders, using logistic regression with forward selection in order to identify those variables most strongly related to the main outcomes (PHQ-9, GAD-2, AUDIT) in each group. We made the selection among parents without any psychological premorbidity according to answers to the four questions asked, separately within the groups of suicide-bereaved and non- 
Table 1 History of psychological premorbidity among suicide-bereaved and non-bereaved parents

\begin{tabular}{|c|c|c|c|}
\hline $\begin{array}{l}\text { Psychological morbidity with first } \\
\text { appearance more than } 10 \text { years earlier }\end{array}$ & $\begin{array}{l}\text { Suicide-bereaved } \\
\text { Number/total number (\%) }\end{array}$ & $\begin{array}{l}\text { Non-bereaved } \\
\text { Number/total number (\%) }\end{array}$ & $\begin{array}{l}\text { Relative } \\
\text { risks (Cl 95\%) }\end{array}$ \\
\hline Psychological problems*,$\dagger$ & $71 / 659(11)$ & $38 / 373(10)$ & $1.0(0.7$ to 1.5$)$ \\
\hline Psychiatric diagnosis $†, \ddagger$ & $45 / 651(7)$ & $18 / 373(5)$ & $1.4(0.8$ to 2.4$)$ \\
\hline Medication against anxiety†,§ & $52 / 657(8)$ & $24 / 377(6)$ & $1.2(0.8$ to 2.0$)$ \\
\hline Medication against low mood $\uparrow, \emptyset$ & $61 / 655(9)$ & $23 / 373(6)$ & $1.5\left(1.0^{* *}\right.$ to 2.4$)$ \\
\hline Any of the abovet† & $94 / 663(14)$ & $51 / 377(14)$ & $1.0(0.8$ to 1.4$)$ \\
\hline
\end{tabular}

*Have you ever received treatment for psychological problems such as depression, anxiety, psychosis or personality disorder? (treatment was defined as treatment prescribed by a physician, eg, medication, electroconvulsive therapy (ECT) or conversational therapy). If yes, when did you receive your first treatment?

†The answer categories were 'more than 10 years earlier' and 'during the last 10 years' for the non-bereaved and 'more than 10 years earlier', 'during the last 10 years, before my child's death' and 'during the last 10 years, after my child's death' for the bereaved.

†Have you ever been given a psychiatric diagnosis, for example, depression, panic disorder, psychosis or personality disorder? If yes, when were you given your first diagnosis?

§Have you during a period of your life medicated against anxiety? If yes, when did you take your first medication?

ПHave you during a period of your life medicated against low mood or depression? If yes, when did you take your first medication?

${ }^{\star *}$ The exact confidence limit is 0.95 .

††Referred to as with premorbidity in table 3.

bereaved parents. Since we wanted to maximise the possibility of finding other explanatory factors that could potentially disprove the assumed effect of bereavement, we used a liberal inclusion criterion allowing variables up to the $15 \%$ significance level entry. For those with and without psychological premorbidity, we then formed one final model for each outcome utilising all variables that had been identified as associated with the outcome within at least one of the suicide-bereaved or nonbereaved groups and report the resulting adjusted ORs.

Table 2 Psychological morbidity among suicide-bereaved and non-bereaved parents

\begin{tabular}{|c|c|c|c|}
\hline & $\begin{array}{l}\text { Suicide-bereaved } \\
\text { Number/total } \\
\text { number }(\%)\end{array}$ & $\begin{array}{l}\text { Non-bereaved } \\
\text { Number/total } \\
\text { number (\%) }\end{array}$ & $\begin{array}{l}\text { Relative risks } \\
\text { RR (Cl 95\%) }\end{array}$ \\
\hline \multicolumn{4}{|l|}{ Anxiety and depressive symptoms } \\
\hline \multicolumn{4}{|l|}{ Single item questions* } \\
\hline Persisting anxiety $†$ & $41 / 664(6)$ & $4 / 377(1)$ & $5.8(2.1$ to 16.1$)$ \\
\hline Anxiety attacks $\ddagger$ & $53 / 664(8)$ & $5 / 377(1)$ & 6.0 (2.4 to14.9) \\
\hline Awakening with anxiety during nightł & $40 / 663(6)$ & $5 / 377(1)$ & 4.5 (1.8 to11.4) \\
\hline Awakening with anxiety in the morning $\neq$ & $46 / 664(7)$ & 2/377 (<1) & 13.0 (3.2 to 53.5$)$ \\
\hline Low or depressive mood $\dagger$ & $141 / 663(21)$ & $21 / 377(6)$ & 3.8 (2.5 to 5.9$)$ \\
\hline \multicolumn{4}{|l|}{ Psychometric scales } \\
\hline Depression (PHQ-9)§ & $115 / 655(18)$ & $28 / 374(7)$ & 2.3 (1.6 to 3.5$)$ \\
\hline Anxiety (GAD-2)ף & $139 / 658(21)$ & $22 / 374(6)$ & 3.6 (2.3 to 5.5$)$ \\
\hline Hazardous alcohol consumption (AUDIT) ** & $76 / 643(12)$ & $28 / 375(7)$ & 1.6 (1.0 to 2.4$)$ \\
\hline \multicolumn{4}{|l|}{ Medication single item questions* and PHQ-9 } \\
\hline Sleeping medication ${ }^{\dagger}$ & $82 / 664(12)$ & $20 / 377(5)$ & $2.3(1.5$ to 3.7$)$ \\
\hline Antidepressant medication† & $99 / 664(15)$ & $13 / 375(3)$ & 4.3 (2.4 to 7.6$)$ \\
\hline Anxiolytic medication $†$ & $49 / 662(7)$ & $8 / 375(2)$ & 3.5 (1.7 to 7.2$)$ \\
\hline $\begin{array}{l}\text { Antidepressant medication and/or } \\
\text { depression†,§ }\end{array}$ & $167 / 665(25)$ & $35 / 377(9)$ & 2.7 (1.9 to 3.8$)$ \\
\hline \multicolumn{4}{|c|}{$\begin{array}{l}\text { `Self-rated prevalence of symptoms during the preceding month with answering alternatives ranging from 'no', 'yes occasionally', 'yes } 1-3 \\
\text { times or days a week', 'yes } 4-5 \text { times or days a week', and 'yes } 6-7 \text { times or days a week'. } \\
\text { †'Yes } 1 \text { day a week' or more often. } \\
\text { f'Yes } 1 \text { time a week' or more often. } \\
\text { §The nine-item depression scale (PHQ-9), score } 10 \text { or higher (range from } 0 \text { to } 27 \text { ). The answering categories were slightly modified from 'not } \\
\text { at all', 'several days', 'more than half the days', 'nearly every day' to 'not at all', ' } 1-3 \text { days a week', ' } 4-5 \text { days a week', and ' } 6-7 \text { days a week', } \\
\text { using the same system for scoring. The calculated scores were based on self-reported data. } \\
\text { १The two-item Generalised Anxiety Disorder scale (GAD-2) score } 2 \text { or higher (range from } 0 \text { to } 6 \text { ). The answering categories were slightly } \\
\text { modified as described above, using the same system for scoring. The calculated scores were based on self-reported data. } \\
\text { **The Alcohol Use Disorders Identification Test (AUDIT) scores } 8 \text { or higher (range from } 0 \text { to } 40 \text { ). The calculated scores were based on } \\
\text { self-reported data. } \\
\text { AUDIT,alcohol use disorders identification test; GAD, generalised anxiety disorder; PHQ, Patient Health Questionnaire. }\end{array}$} \\
\hline
\end{tabular}


Table 3 Unadjusted and adjusted relative risks and ORs for outcome of depression (PHQ-9), anxiety (GAD-2) and hazardous alcohol consumption (AUDIT) among suicide-bereaved and non-bereaved parents, with and without psychological premorbidity

\begin{tabular}{|c|c|c|c|c|c|c|c|c|c|c|c|}
\hline & \multicolumn{9}{|c|}{ RR (95\% Cl) adjusted for } & \multicolumn{2}{|l|}{ OR (95\% Cl) } \\
\hline & $\begin{array}{l}\mathrm{RR}(95 \% \mathrm{Cl}) \\
\text { Unadjusted }\end{array}$ & Sex & Age & $\begin{array}{l}\text { Residence } \\
\text { area }\end{array}$ & Civil status & $\begin{array}{l}\text { Level of } \\
\text { education }\end{array}$ & $\begin{array}{l}\text { Source of } \\
\text { income }\end{array}$ & $\begin{array}{l}\text { Physical } \\
\text { activity }\end{array}$ & $\begin{array}{l}\text { Social } \\
\text { activity }\end{array}$ & Unadjusted & $\begin{array}{l}\text { Adjusted for } \\
\text { multiple* }\end{array}$ \\
\hline \multicolumn{12}{|c|}{ With premorbidity $†$} \\
\hline PHQ-9 & 2.6 & 2.6 & 2.8 & 2.5 & 2.5 & 2.5 & 2.3 & 2.3 & 2.2 & 3.5 & $2.8 \ddagger$ \\
\hline$\geq 10$ & (1.2 to 5.4$)$ & (1.2 to 5.3$)$ & (1.3 to 5.8$)$ & (1.2 to 5.3$)$ & (1.2 to 5.2$)$ & (1.2 to 5.2$)$ & (1.1 to 4.9$)$ & (1.1 to 4.7 ) & (1.1 to 4.7$)$ & $(1.4$ to 8.5$)$ & (1.0 to 7.4$)$ \\
\hline GAD-2 & 3.8 & 3.8 & 3.7 & 3.7 & 3.5 & 3.8 & 3.3 & 3.4 & 4.2 & 5.5 & $4.7 \S$ \\
\hline$\geq 2$ & (1.6 to 9.0$)$ & (1.6 to 9.0$)$ & (1.5 to 9.0$)$ & (1.6 to 9.0$)$ & (1.5 to 8.4$)$ & (1.6 to 9.1 ) & (1.4 to 8.0$)$ & (1.4 to 8.2$)$ & (1.6 to 11.0$)$ & (2.0 to 15.0$)$ & (1.5 to15.2) \\
\hline AUDIT & 1.4 & 1.4 & 1.2 & 1.5 & 1.3 & 1.4 & 1.6 & 1.1 & 1.2 & 1.5 & 1.01 \\
\hline$\geq 8$ & (0.5 to 3.8$)$ & (0.5 to 3.6$)$ & (0.5 to 3.3$)$ & (0.6 to 3.8$)$ & (0.5 to 3.5$)$ & (0.5 to 3.7$)$ & (0.6 to 4.2$)$ & (0.4 to 3.1$)$ & (0.4 to 3.2$)$ & (0.5 to 4.5$)$ & $(0.3$ to 3.5$)$ \\
\hline \multicolumn{12}{|c|}{ Without premorbidity } \\
\hline PHQ-9 & 2.3 & 2.2 & 2.3 & 2.3 & 2.3 & 2.3 & 2.1 & 2.3 & 2.1 & 2.5 & $2.2 \ddagger$ \\
\hline$\geq 10$ & (1.4 to 3.6$)$ & (1.4 to 3.5$)$ & (1.4 to 3.6$)$ & (1.4 to 3.6$)$ & (1.4 to 3.6$)$ & (1.4 to 3.6$)$ & (1.3 to 3.4$)$ & (1.5 to 3.6$)$ & (1.3 to 3.3$)$ & (1.5 to 4.0$)$ & (1.3 to 3.7$)$ \\
\hline$\overline{G A D}-2$ & 3.5 & 3.4 & 3.5 & 3.5 & 3.5 & 3.5 & 3.3 & 3.5 & 3.3 & 4.0 & $3.7^{\S}$ \\
\hline$\geq 2$ & (2.1 to 5.7 ) & (2.1 to 5.6$)$ & (2.1 to 5.7$)$ & (2.2 to 5.8$)$ & (2.2 to 5.8$)$ & (2.1 to 5.8$)$ & (2.0 to 5.5$)$ & (2.1 to 5.7 ) & (2.0 to 5.4$)$ & (2.4 to 6.9$)$ & (2.2 to 6.4 ) \\
\hline$\overline{A U D I T}$ & 1.6 & 1.6 & 1.6 & 1.6 & 1.6 & 1.6 & 1.6 & 1.6 & 1.5 & 1.7 & $1.7 \ddagger$ \\
\hline$\geq 8$ & (1.0 to 2.6$)$ & (1.0 to 2.5$)$ & (1.0 to 2.5$)$ & (1.0 to 2.6$)$ & (1.0 to 2.6$)$ & (1.0 to 2.5$)$ & (1.0 to 2.6 ) & (1.0 to 2.5$)$ & (1.0 to 2.5$)$ & (1.0 to 2.8$)$ & (1.0 to 2.8$)$ \\
\hline
\end{tabular}

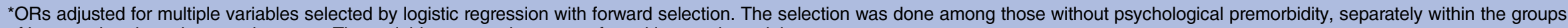
of bereaved and non-bereaved parents. The variables sex and age were forced into each model.

tParticipants were categorised 'With premorbidity' if they, more than 10 years earlier: had their first treatment for psychological morbidity such as depression, anxiety, psychosis or personality

disorder (treatment defined as treatment prescribed by a physician such as medication, electroconvulsive therapy (ECT) or conversational therapy) or, had been given their first psychiatric

diagnosis such as depression, panic attacks, psychosis or personality disorder or used medication against anxiety or depression.

$\ddagger$ Variables selected in both bereaved and non-bereaved: (sex, age), source of income, social activity

$\S$ Variables selected within the bereaved group: (sex, age), source of income, physical activity, social activity.

ףVariables selected in both bereaved and non-bereaved: (sex, age), source of income. Variables selected within the bereaved group: education, physical activity. Variables selected within the non-bereaved group: social activity.

AUDIT,alcohol Use disorders identification test; GAD, generalised anxiety disorder; PHQ, Patient Health Questionnaire; RR, relative risk. 
Table 4 General health and well-being among suicide-bereaved and non-bereaved parents

\begin{tabular}{|c|c|c|c|}
\hline & $\begin{array}{l}\text { Suicide-bereaved } \\
\text { Number/total number (\%) }\end{array}$ & $\begin{array}{l}\text { Non-bereaved } \\
\text { Number/total number (\%) }\end{array}$ & $\begin{array}{l}\text { Relative } \\
\text { risk }(95 \% \mathrm{Cl})\end{array}$ \\
\hline \multicolumn{4}{|l|}{ Quality of life during the last month* } \\
\hline None to low & $126 / 662(19)$ & $31 / 376(8)$ & 2.3 (1.6 to 3.3$)$ \\
\hline \multicolumn{4}{|l|}{ Well-being during the last month $†$} \\
\hline No to yes, a little & 228/660 (35) & $53 / 377(14)$ & 2.5 (1.9 to 3.2$)$ \\
\hline \multicolumn{4}{|c|}{ Meaningful life during the last month $\ddagger$} \\
\hline No to yes, a little & $190 / 658(29)$ & $37 / 377(10)$ & 2.9 (2.1 to 4.0$)$ \\
\hline \multicolumn{4}{|c|}{ Psychological health during the last month* } \\
\hline None to low & $136 / 662(21)$ & 29/377 (8) & 2.7 (1.8 to 3.9$)$ \\
\hline \multicolumn{4}{|c|}{ Physical health during the last month* } \\
\hline None to low & $148 / 661(22)$ & $61 / 376(16)$ & $1.4(1.0$ to 1.8$)$ \\
\hline \multicolumn{4}{|l|}{ Feelings of guilt* } \\
\hline Yes, 1-3 days a week or more & $110 / 666(17)$ & 10/374 (3) & 6.2 (3.3 to 11.7$)$ \\
\hline \multicolumn{4}{|l|}{ Fear of next-of-kin's death $\dagger$} \\
\hline Yes, 1-3 days a week or more & $96 / 666(14)$ & $14 / 373(4)$ & 3.8 (2.2 to 6.6$)$ \\
\hline
\end{tabular}

We performed statistical tests at the $5 \%$ significance level, unless otherwise stated, and excluded individuals with missing data in each respective calculation. All statistical analyses were performed with the IBM SPSS Statistics software, V.19.0.

\section{RESULTS}

\section{Participants}

The questionnaires were returned by 666 of the 915 (73\%) suicide-bereaved parents and 377 of the 508 (74\%) non-bereaved parents. The suicide-bereaved and non-bereaved parents had similar background characteristics concerning: age, gender, residence area, family constellation, number of children, country of birth, level of education, source of income, yearly income and religiosity (table 5 ).

\section{Primary outcomes}

Psychological premorbidity, as measured by answers to single-item questions, did not differ significantly between the groups of suicide-bereaved and nonbereaved parents. In total 94 of 663 (14\%) suicidebereaved and 51 of $377(14 \%)$ non-bereaved parents (RR $1.0 ; 95 \%$ CI 0.8 to 1.4 ) reported that they had received their first treatment for psychological problems or had been given a psychiatric diagnosis more than 10 years earlier, although the bereaved parents had somewhat higher prevalences for all the individual single-item questions (table 1).

\section{Self-reported anxiety and depressive symptoms}

The prevalence of moderate-to-severe depression, as measured by PHQ-9, was 115 of 655 (18\%) among suicidebereaved parents in comparison with 28 of $374(7 \%)$ non-bereaved parents, resulting in a relative risk of 2.3 (95\% CI 1.6 to 3.5 ; table 2 ). Split by sex, the prevalence of moderate-to-severe depression was 87 of 375 (23\%) in suicide-bereaved mothers, 22 of 186 (12\%) in nonbereaved mothers, 28 of $280(10 \%)$ in suicide-bereaved fathers and 6 of $160(4 \%)$ in non-bereaved fathers (data not shown in tables). When stratified according to psychological premorbidity, the prevalence of moderateto-severe depression among those with premorbidity was 33 of $93(35 \%)$ among the bereaved versus 7 of $51(14 \%)$ among the non-bereaved (RR 2.6; 95\% CI 1.2 to 5.4), while among those without premorbidity the corresponding prevalences were 82 of 560 (15\%) among the bereaved versus 21 of $323(7 \%)$ among the non-bereaved (RR 2.3; 95\% CI 1.4 to 3.6 ). The statistically significant difference between bereaved and non-bereaved parents remained after adjusting for the following known riskfactors for depression: sex, age, residential area, civil status, level of education, source of income, physical activity and social activity (table 3 ).

\section{Secondary outcomes}

In comparison with the non-bereaved parents, the suicide-bereaved parents showed a higher prevalence of all negative outcomes, for which all differences except harmful alcohol consumption and physical health were statistically significant (tables 2-4). We found the risk of feelings of guilt (without a specified cause) to be more than six times higher among suicide-bereaved parents, and the risk of fear of next-of-kin's death to be about four times higher (table 4). Among the suicidebereaved, 457 of $651(70 \%)$ reported feelings of guilt for the child's death and 372 of $642(58 \%)$ believed that they could have prevented the suicide. One of 4, 164 of $666(25 \%)$ reported that their child had self-harmed 
Table 5 Participation and characteristics of suicide-bereaved and non-bereaved parents

\begin{tabular}{|c|c|c|c|}
\hline Participants & $\begin{array}{l}\text { Suicide-bereaved } \\
\mathrm{n}=666\end{array}$ & $\begin{array}{l}\text { Non-bereaved } \\
\mathrm{n}=377\end{array}$ & p Value \\
\hline Sex-n (\%) & & & $0.630^{*}$ \\
\hline Fathers & $283(42)$ & $166(44)$ & \\
\hline Mothers & $383(58)$ & $211(56)$ & \\
\hline \multicolumn{4}{|l|}{ Age-year } \\
\hline Fathers, median (IQR) & $58(53-62)$ & $59(54-62)$ & $0.667 \dagger$ \\
\hline Mothers, median (IQR) & $55(51-59)$ & $54(50-59)$ & $0.161 \dagger$ \\
\hline Children-n (\%)‡ & & & $0.887^{*}$ \\
\hline One child & $71(11)$ & $43(11)$ & \\
\hline Two children & $241(36)$ & $139(37)$ & \\
\hline Three or more children & $350(53)$ & $193(51)$ & \\
\hline Not stated & $4(<1)$ & $2(<1)$ & \\
\hline Family constellation at time of study-n (\%) & & & $0.964^{*}$ \\
\hline Living with a partner & $477(72)$ & $271(72)$ & \\
\hline Has partner but lives alone & $44(7)$ & $28(7)$ & \\
\hline Single & $121(18)$ & $67(18)$ & \\
\hline Widow, widower & $18(3)$ & $11(3)$ & \\
\hline Not stated & $6(<1)$ & $0(0)$ & \\
\hline Residence area-n (\%) & & & $0.365^{\star}$ \\
\hline Rural & $162(24)$ & $77(20)$ & \\
\hline Village (population <10 000) & $153(23)$ & $97(26)$ & \\
\hline Small town (population <50 000) & $128(19)$ & 73 (19) & \\
\hline Town (population <200 000) & $117(18)$ & $62(16)$ & \\
\hline Larger town (population >200 000) & $97(15)$ & $68(18)$ & \\
\hline Not stated & $9(1)$ & $0(0)$ & \\
\hline Country of birth-n (\%) & & & $0.003^{\star}$ \\
\hline Born in Sweden & $629(94)$ & $371(98)$ & \\
\hline Born in other Nordic country & $36(6)$ & $6(2)$ & \\
\hline Not stated & $1(<1)$ & $0(0)$ & \\
\hline Level of education-n (\%) & & & $0.625^{\star}$ \\
\hline Elementary school or less & $146(22)$ & 73 (19) & \\
\hline Junior college & $271(41)$ & $158(42)$ & \\
\hline College or university (<3 years) & $82(12)$ & $55(15)$ & \\
\hline College or university (>3 years) & $159(24)$ & $91(24)$ & \\
\hline Not stated & $8(1)$ & $0(0)$ & \\
\hline Source of income-n (\%) & & & $0.060^{*}$ \\
\hline Employed or self-employed & $498(75)$ & $303(80)$ & \\
\hline Old-age pension & $59(9)$ & $38(10)$ & \\
\hline Disability pension & $61(9)$ & $21(6)$ & \\
\hline Unemployment fund & $25(4)$ & $6(2)$ & \\
\hline Other & $16(2)$ & $9(2)$ & \\
\hline Not stated & $7(1)$ & $0(0)$ & \\
\hline Yearly income in Swedish crowns-n (\%) & & & $0.189^{\star}$ \\
\hline 0-99 000 SEK & $34(5)$ & $10(3)$ & \\
\hline 100 000-199 000 SEK & $120(18)$ & $64(17)$ & \\
\hline 200 000-39 9000 SEK & $388(58)$ & $240(64)$ & \\
\hline 400000 SEK or more & $109(16)$ & 59 (16) & \\
\hline Not stated & $15(2)$ & $4(1)$ & \\
\hline Religion-n (\%) & & & $0.252^{*}$ \\
\hline Do not believe in God & $355(53)$ & $216(57)$ & \\
\hline Believes in God & $287(43)$ & $150(40)$ & \\
\hline Not stated & $24(4)$ & $11(3)$ & \\
\hline
\end{tabular}

and 150 of $666(23 \%)$ that their child had tried to commit suicide during the year prior to the suicide. Seventy-nine of $666(12 \%)$ also reported that their child had been in contact with the healthcare system several times as a result of suicide-attempts during the year prior to the suicide. One of 2, 339 of $666(51 \%)$ were 
anxious over the child's psychological health and 294 of $666(44 \%)$ had worried that their child might commit suicide during the month prior to the suicide. The suicide was perceived as somewhat expected by 259 of $666(39 \%)$ parents and 424 of $666(64 \%)$ believed that their child suffered from a psychiatric disease such as depression, anxiety disorder, personality disorder, psychosis or substance abuse. We found that the majority of suicides were made by violent means such as hanging, strangulation and suffocation $(53 \%)$, by moving vehicles $(13 \%)$, jumping from a height $(7 \%)$ or by firearm discharge $(7 \%)$ (data not shown in the tables).

\section{DISCUSSION}

In our nationwide survey of 666 suicide-bereaved and 377 non-bereaved parents, the bereaved did not have a higher prevalence of psychological premorbidity than the non-bereaved. However, the $14 \%$ of the bereaved with premorbidity more often reported several forms of premorbidity as compared to the $14 \%$ of the nonbereaved with premorbidity, possibly reflecting more severe afflictions. Among those without premorbidity, the bereaved parents had a more than twofold higher risk of moderate-to-severe depression 2-5 years after the loss, as measured by PHQ-9. The same was found for the more than threefold higher risk of anxiety, as measured by GAD-2 (table 3). We found an increased risk of depression and anxiety in both groups of suicide-bereaved, those with psychological premorbidity and those without.

\section{Comparison with other studies}

We found two population-based studies that investigated psychological premorbidity among suicide-bereaved and non-bereaved parents using registries on psychiatric admissions and diagnoses: Stenager and Qin's ${ }^{15}$ study on 4142 individuals aged 9-35 years who committed suicide in Denmark during the period 1981 to 1997 and Bolton et $a l \mathrm{~s}^{16}$ study of 1415 suicide-bereaved parents in Manitoba, Canada between 1997 and 2007. Stenager and $\operatorname{Qin}^{15}$ found that about $6 \%$ of the suicide-bereaved parents and about 3\% of the non-bereaved controls had been admitted to a psychiatric hospital 10 years prior to the suicide and about $1.1 \%$ of the suicide-bereaved and $0.5 \%$ of the non-bereaved had been admitted within the past 3 years. In Bolton et al $\mathrm{s}^{16}$ study, $28 \%$ of the suicidebereaved parents had had a mental disorder 2 years prior to the suicide, according to the registers. Bolton et al also showed that $15 \%$ of the suicide-bereaved parents had been diagnosed with depression 2 years prior to the suicide in comparison to $11 \%$ of the control parents who had been diagnosed with depression at the same time. Two years after the suicide, the prevalence rose to $31 \%$ among the suicide-bereaved parents, while the control parents' prevalence barely changed $(10 \%)$. Bolton et al suggest that the suicide-bereaved parents have a premorbidity due to shared genetic and environmental factors as one part of the explanation, but they also recognise that the parents might have stress-related psychopathology due to factors that preceded the suicide. In our study, one of two suicide-bereaved parents had experienced anxiety over their child's psychological health and risk for suicide $(44 \%)$ during the year prior to the suicide. Also, one of four had experienced that their child self-harmed and tried to commit suicide (23\%), sometimes repeatedly during a long period of time prior to the suicide. To diminish the risk of capturing effects directly related to a stressful time of parenting during the years preceding the suicide, we chose to measure the debut of psychological premorbidity in the period ending more than 10 years before the suicide. The discrepancy in results might be related to the measurements as well as differences among populations. Our results are nationwide and self-reported. We included psychological treatments and psychotropic drugs prescribed by a physician in addition to psychiatric diagnoses, cases not always registered in inpatient or outpatient registers. One may hypothesise that cases of psychological morbidity reported in registers might be more severe and that severe psychiatric conditions are more prevalent among a subpopulation of the suicidebereaved parents compared to controls.

Two longitudinal surveys found that while a history of depression is associated with recurrence of depression, one brief bereavement-related depressive episode is not. ${ }^{30} 31$ In a sample from a longitudinal survey including the US general population, ${ }^{30} 865$ of 43093 participants with a lifetime history of one brief bereavementrelated depressive episode reported major depression 3 years later. In comparison, 2320 of 27074 participants with no history of depression reported major depression at follow-up, resulting in a non-significant difference (RR 0.85 ; $95 \%$ CI 0.52 to 1.59 ). Similar results were found in Wakefield's longitudinal survey. ${ }^{31}$ In contrast, our data suggest an elevated risk of depression 2-5 years after the loss among suicide-bereaved parents compared to non-bereaved parents, regardless of psychological premorbidity. One explanation for this discrepancy might be that our participants had lost a child and that death by suicide like other traumatic deaths often is associated with a particularly difficult grieving process. ${ }^{32}$ This is supported by Kessling et $a l_{\mathrm{s}}{ }^{2}$ case-control study on major life events and first-time admission for depression, which included 13006 depressed patients and 260108 age-matched and sex-matched controls. In this study, suicide of a family member was associated with 1.95 relative risk ( $95 \%$ CI 1.30 to 2.92) of being first-time admitted for depression, whereas death of a family member by causes other than suicide was associated with a nonsignificant relative risk of 1.11 (95\% CI 0.91 to 1.35 ). We found a high risk of depression after parental bereavement in two register-based studies, both only including parents without previous psychiatric admissions. $\mathrm{Li}$ et $a l^{3}$ followed more than 1 million parents during 1970 to 1999 and found that parents who lost a child, age 6 years or older, had a higher relative risk of being 
hospitalised for affective disorder; 2.72 (95\% CI 1.54 to 4.81) among mothers and 1.85 (95\% CI 0.59 to 5.75) among fathers. Kessling et $a l \mathrm{~s}^{2}$ case-control study stated that 26 of 13006 individuals admitted with depression had experienced a child's suicide in comparison with 257 of 260108 individuals who were not admitted, giving a relative risk of 1.95 (95\% CI 1.30 to 2.92).

\section{Strengths and limitations}

Our study has several strengths: one is the large sample of suicide-bereaved parents and matched controls, all identified through nationwide high-quality registers. Another is the high participation rate among suicidebereaved and non-bereaved men and women. The background characteristics among the respondents were remarkably similar among the bereaved and nonbereaved. We matched the group of suicide-bereaved with the group of non-bereaved on important, possible confounding sociodemographic variables and the responding groups were similar also on factors that we did not match for (table 5). Our study also has limitations. The questions regarding psychological premorbidity cover a large time-span and the answers might be affected by recall-induced problems due to time and informants' experiences. To reduce this risk, we asked specific questions about medication, psychiatric diagnoses and treatments prescribed by a physician rather than general questions about psychological morbidity. We also lack information about possible confounders related to personality, since questions on personality were perceived as difficult to grasp by the parents in the preparatory study. ${ }^{18}$ We chose not to include personality inventories in the questionnaire due to their size. Our main outcome psychological morbidity is common in the general population and we wanted a demographically relevant group of parents for comparison of psychological premorbidity as well as current psychological morbidity. Using a comparison group of only nonbereaved parents not including parents bereaved by other death causes can be disputed. A disadvantage is that we cannot disentangle how much of the elevated psychological morbidity can be explained by loss of a son or daughter in general, and loss to suicide specifically. We lack information about the prevalence of psychological morbidity among non-participants and consequently about whether their participation would have affected our findings. We addressed the threats to validity by employing epidemiological methods as transferred to this field by the hierarchical step-model for study design, analysis and data interpretation. ${ }^{33}$ Efforts to reduce the problem of misclassification included a thorough prestudy, developing and testing the questions and the psychometric scales in close collaboration with parents from the study population. ${ }^{18}$ Our main outcomes were measured by psychometric as well as studyspecific questions based on DSM-IV with similar results, and we have no reason to believe that the suicidebereaved and non-bereaved differ systematically in their response to these questions. It is likely that the fundamental manifestations of grief are universal, but still, generalisation to other populations may be compromised by culture-specific issues.

\section{CONCLUSION}

Depression can be prevented and treated, but it is yet to be established if the methods used are as effective in the subgroups of parents who are suicide-bereaved and depressed. Our finding that the suicide-bereaved parents' prevalence of psychological premorbidity was not higher than the non-bereaved parents' prevalence adds important information for further intervention studies. The knowledge is also valuable for contradicting the prejudiced assumption that suicide primarily occurs in especially vulnerable families.

Acknowledgements The authors would like to thank the parents who participated in the study for their willingness and bravery, they also thank Else Lundin and Jonna Lindsjö at Karolinska Institutet for their administrative support in the study, and Lawrence Lundgren PhD, Professor Emeritus, University of Rochester, for linguistic revision of the manuscript.

Contributors PO, BR, UN and GS designed the study. PO performed the data collection supervised by GS and UN. TN and PO analysed the data. PO wrote the first draft of the report. UN, GS, BR and TN commented on the report, which PO and UN revised. All authors contributed to the discussion and have seen the final version of the paper. PO (guarantor) and all the coauthors had full access to all of the data in the study and take responsibility for the integrity of the data and the accuracy of the data analysis.

Funding The study was supported by The Swedish Council for Working Life Social Research (FAS), ALF Grants, County Council of Stockholm and Swedish Lundbeck foundation. The researchers conducted this study totally independent of the funding body.

Competing interests PO and UN have received research grants from The Swedish Council for Working Life Social Research (FAS), ALF Grants, County Council of Stockholm and Swedish Lundbeck foundation for the submitted work; BR has been paid for developing and delivering educational presentations for Lundbeck and AstraZeneca.

Ethics approval The regional ethics review board in Stockholm approved of the study (Dnr: 2006/284-31).

Provenance and peer review Not commissioned; externally peer reviewed.

Data sharing statement No additional data are available.

Open Access This is an Open Access article distributed in accordance with the Creative Commons Attribution Non Commercial (CC BY-NC 3.0) license, which permits others to distribute, remix, adapt, build upon this work noncommercially, and license their derivative works on different terms, provided the original work is properly cited and the use is non-commercial. See: http:// creativecommons.org/licenses/by-nc/3.0/

\section{REFERENCES}

1. Dyregrov K, Nordanger D, Dyregrov A. Predictors of psychosocial distress after suicide, SIDS and accidents. Death Stud 2003;27:143-65.

2. Kessing LV, Agerbo E, Mortensen PB. Does the impact of major stressful life events on the risk of developing depression change throughout life? Psychol Med 2003;33:1177-84.

3. Li J, Laursen TM, Precht DH, et al. Hospitalization for mental illness among parents after the death of a child. $N$ Engl $J$ Med 2005;352:1190-6.

4. Li J, Precht DH, Mortensen PB, et al. Mortality in parents after death of a child in Denmark: a nationwide follow-up study. Lancet 2003;361:363-7. 
5. Murphy SA, Johnson LC, Chung IJ, et al. The prevalence of PTSD following the violent death of a child and predictors of change 5 years later. J Trauma Stress 2003;16:17-25.

6. Runeson B, Åsberg M. Family history of suicide among suicide victims. Am J Psychiatry 2003;160:1525-6.

7. Stroebe M, Schut H, Stroebe W. Health outcomes of bereavement Lancet 2007;370:1960-73.

8. Feigelman W, Jordan JR, Gorman BS. How they died, time since loss, and bereavement outcomes. Omega 2008;58: 251-73.

9. Jordan JR. Is suicide bereavement different? A reassessment of the literature. Suicide Life Threat Behav 2001;31:91-102.

10. Clark S. Bereavement after suicide-how far have we come and where do we go from here? Crisis 2001;22:102-8.

11. Cvinar JG. Do suicide survivors suffer social stigma: a review of the literature. Perspect Psychiatr Care 2005;41:14-21.

12. Baldessarini RJ, Hennen J. Genetics of suicide: an overview. Harv Rev Psychiatry 2004;12:1-13.

13. Brent DA, Mann JJ. Familial pathways to suicidal behaviorunderstanding and preventing suicide among adolescents. $N$ Engl J Med 2006;355:2719-21.

14. Tidemalm D, Runeson B, Waern M, et al. Familial clustering of suicide risk: a total population study of 11.4 million individuals. Psychol Med 2011;1:1-8.

15. Stenager K, Qin P. Individual and parental psychiatric history and risk for suicide among adolescents and young adults in Denmark: a population-based study. Soc Psychiatry Psychiatr Epidemiol 2008;43:920-6.

16. Bolton JM, Au W, Leslie WD, et al. Parents bereaved by offspring suicide: a population-based longitudinal case-control study. JAMA Psychiatry 2013;70:158-67.

17. Forte AL, Hill M, Pazder R, et al. Bereavement care interventions: a systematic review. BMC Palliat Care 2004;3:3.

18. Omerov P, Steineck G, Runeson B, et al. Preparatory studies to a population-based survey of suicide-bereaved parents in Sweden. Crisis 2013:34:200-10.

19. Ludvigsson JF, Otterblad-Olausson P, Pettersson BU, et al. The Swedish personal identity number: possibilities and pitfalls in healthcare and medical research. Eur J Epidemiol 2009;24: 659-67.
20. Rådestad I, Surkan PJ, Steineck G, et al. Long-term outcomes for mothers who have or have not held their stillborn baby. Midwifery 2009;25:422-9.

21. Kreicbergs U, Valdimarsdóttir U, Onelöv E, et al. Talking about death with children who have severe malignant disease. $N$ Engl J Med 2004;351:1175-86.

22. Hauksdóttir A, Steineck G, Fürst CJ, et al. Towards better measurements in bereavement research: order of questions and assessed psychological morbidity. Palliat Med 2006;20:11-16.

23. Kroenke K, Spitzer RL, Williams JB, et al. Anxiety disorders in primary care: prevalence, impairment, comorbidity, and detection. Ann Intern Med 2007;146:317-25.

24. Kroenke K, Spitzer RL, Williams JB. The PHQ-9: validity of a brief depression severity measure. J Gen Intern Med 2001;16:606-13.

25. Allen JP, Litten RZ, Fertig JB, et al. A review of research on the Alcohol Use Disorders Identification Test (AUDIT). Alcohol Clin Exp Res 1997;21:613-19.

26. American Psychiatric Association (APA). Diagnostiska kriterier enligt DSM-IV (Quick reference to the Diagnostic and Statistical Manual of Mental Disorders, (DSM-IV). 4th edn. Danderyd: Pilgrim Press, 1995:123-68.

27. Arroll B, Goodyear-Smith F, Crengle $S$, et al. Validation of PHQ-2 and PHQ-9 to screen for major depression in the primary care population. Ann Fam Med 2010;8:348-53.

28. Donker $\mathrm{T}$, van Straten A, Marks I, et al. Quick and easy self-rating of generalized anxiety disorder: validity of the Dutch web-based GAD-7, GAD-2 and GAD-SI. Psychiatry Res 2011;188:58-64.

29. Reinert DF, Allen JP. The alcohol use disorders identification test: an update of research findings. Alcohol Clin Exp Res 2007;31:185-99.

30. Mojtabai R. Bereavement-related depressive episodes: characteristics, 3-year course, and implications for the DSM-5. Arch Gen Psychiatry 2011;68:920-8.

31. Wakefield JC, Schmitz MF. Recurrence of depression after bereavement-related depression: evidence for the validity of DSM-IV bereavement exclusion from the Epidemiologic Catchment Area Study. J Nerv Ment Dis 2012;200:480-5.

32. Kristensen P, Weisaeth L, Heir T. Bereavement and mental health after sudden and violent losses: a review. Psychiatry 2012;75:76-97.

33. Steineck G, Hunt H, Adolfsson J. A hierarchical step-model for causation of bias-evaluating cancer treatment with epidemiological methods. Acta Oncol 2006:45:421-9. 